\title{
BASC-3 F Index
}

National Cancer Institute

\section{Source}

National Cancer Institute. BASC-3 FIndex. NCI Thesaurus. Code C159860.

A classically derived infrequency scale, designed to assess the possibility that a rater has depicted a child's behavior in an inordinately negative fashion. 